\title{
Effect of home-based exercise program on lymphedema and quality of life in female postmastectomy patients: Pre-post intervention study
}

\author{
Ajay P. Gautam, MPT; ${ }^{1-2 *}$ Arun G. Maiya, PhD, MPT; ${ }^{1}$ Mamidipudi S. Vidyasagar, MD, DMRT ${ }^{\mathbf{2}}$ \\ ${ }^{1}$ Manipal College of Allied Health Sciences, Department of Physiotherapy, and ${ }^{2}$ Kasturba Medical College, Department \\ of Radiotherapy and Oncology, Manipal University, Manipal, India
}

\begin{abstract}
Lymphedema is a debilitating complication following mastectomy, affecting the arm functions and quality of life (QOL) of breast cancer patients. Studies have shown the beneficial effects of upper-limb exercises on lymphedema in clinical settings. However, there is a dearth of evidence regarding the effect of home-based exercises on lymphedema; therefore, we examined the effect of a home-based exercise program on lymphedema and QOL in postmastectomy patients. Thirty-two female postmastectomy lymphedema patients participated in an individualized home-based exercise program for 8 weeks. Arm circumference, arm volume, and QOL (36-Item Short Form Health Survey) were measured before and after the program. Data were analyzed with the use of paired $t$-tests for circumferential and volumetric measures and Wilcoxon signed ranks tests for QOL. Significance level was set at $p<0.01$ with Bonferroni correction (alpha/n $=$ $0.05 / 5=0.01$ ). Analysis showed a statistically significant improvement in the affected upper-limb circumference and volume ( $122 \mathrm{~mL}$ reduction, $p<0.001)$ and in the QOL scores $(p<$ $0.001)$ at the end of the home-based exercise program. The individualized home-based exercise program led to improvement in affected upper-limb volume and circumference and QOL of postmastectomy lymphedema patients.
\end{abstract}

Key words: breast cancer, home-based exercise program, mastectomy, physiotherapy, postmastectomy lymphedema, progressive resistance exercise, quality of life, rehabilitation, upper-limb exercise, Wilcoxon signed rank test.

\section{INTRODUCTION}

Lymphedema is a chronic, debilitating complication that breast cancer survivors face after breast cancer treat- ment [1-8]. Incidence of secondary arm lymphedema varies from 5 to 56 percent [4,7-12]. About 60 percent of patients who undergo axillary lymph node resection and irradiation will eventually develop lymphedema [13].

Lymphedema develops when the lymphatic flow is impaired and excess fluid and protein accumulate in the interstitial space. The hemodynamic factors at the site of lymphedema may also play a role in its development [1]. Affected women can experience pain, swelling, arm tightness, heaviness of the arm, and recurrent skin infections. If left untreated, lymphedema may predispose the affected limb to the development of other secondary complications like recurrent bouts of cellulitis or lymphangitis, axillary vein thrombosis, severe functional impairment, cosmetic embracement, and lymphangiosarcoma [9]. Breast cancer survivors may find lymphedema more distressing than mastectomy, because hiding the physiological manifestations and loss of function of lymphedema is harder. Overall, these factors lead to decreased quality of life (QOL) for breast cancer survivors [14-15]. Rehabilitative interventions are considered the mainstay for the treatment of

Abbreviations: QOL $=$ quality of life, SF-36 $=36$-Item Short Form Health Survey.

*Address all correspondence to Ajay P. Gautam, MPT; Department of Physiotherapy, Manipal College of Allied Health Sciences, Manipal University, Manipal-576104, Karnataka, India; +91-998-6224897; fax: +91-820-2571915. Email: ajayphysio@gmail.com; ajay78gmpt@yahoo.co.in DOI:10.1682/JRRD.2010.05.0089 
lymphedema, and exercises form an integral component of such rehabilitation [16].

For decades, any kind of strenuous activity has been feared to exacerbate the lymphedema. Current clinical guidelines indicate that women with and at risk for lymphedema should protect the affected arm from overuse [1718]. For this reason, patients with lymphedema avoid using the affected limb, leading to weakness and, hence, predisposing the limb to injury even from small household tasks. Further, such fear poses an additional barrier to patients staying physically active, potentially translating to weight gain, which has been shown to be associated with a worse clinical course for women with lymphedema [5]. However, the evidence shows no association between lymphedema and strenuous activity; hence, upper-limb resistance exercises can help in recovery [19-26]. Previous studies support the view that upper-limb exercises may decrease lymphedema risk by improving the lymphatic return and lymphangiogenesis, i.e., regeneration of new collaterals [27-31]. On the other hand, avoiding activity of the affected limb may lead to poor lymphatic clearance and, hence, stasis of the lymphatic fluid in the affected limb [32]. During the early 6 to 12 months after mastectomy, pain and decreased shoulder movements are more common than lymphedema [33]; these can also be prevented by upper-limb exercises [34]. Particularly, strength training will help not only in recovering arm strength but also in recovering bone mineral loss due to cancer treatment. Inactivity of the affected limb may lead to prolonged arm weakness, poor scapulohumeral function, bone mineral loss and, finally, lymphedema [35-36].

Since the 1990s, efforts have been made by McKenzie and other researchers to disprove the concept that strenuous exercise of the affected upper limb may lead to or worsen lymphedema [19-22]. A few recent clinical trials [19-29], including a well-controlled trial by Schmitz et al. [26], have proved that upper-limb exercises have beneficial effects for lymphedema without exacerbating it. Most of the exercise interventions were provided in hospitals, clinics, or fitness centers. These interventions may not be helpful for those patients who cannot afford the cost of or who lack transportation to institution-based rehabilitation. So, a need existed for the development of an exercise program that these patients could easily follow and perform at their homes.

Evidence is lacking regarding the effect of homebased exercise programs on lymphedema and QOL of breast cancer patients. So, this study was carried out to evaluate the effects of a home-based exercise program on lymphedema and QOL of breast cancer patients. We hypothesized that a structured home-based program of progressive resistance exercises of the upper limbs combined with deep breathing and self-care would help relieve the symptoms of lymphedema and improve the QOL of breast cancer patients. Hence, this study may give valuable evidence supporting the importance of homebased exercise programs in the reduction of postmastectomy lymphedema symptoms and thereby improve the QOL of breast cancer patients.

\section{METHODS}

This study was a pre-post intervention study in which measurements were taken before and after the 8-week home-based exercise program. Convenience sampling was used to select the participants. The contralateral upper limb was used as the control so that any physiological change happening would happen equally on both the limbs.

\section{Subjects}

Breast cancer patients who had undergone mastectomy surgery and had completed neoadjuvant chemoand radiation therapy from March 2006 to February 2008 were referred to the study by the concerned oncologist and oncology surgeon. We screened 137 patients for the inclusion and exclusion criteria given subsequently; of these, 38 met the ideal inclusion criteria. Six were lost to follow up. Therefore, a total of 32 patients (all women) completed the exercise program. The flow of participants through the study is shown in the Figure.

\section{Inclusion and Exclusion Criteria}

Patients were included if they had undergone unilateral mastectomy and completed chemo- and radiation therapy for stage I or II breast cancer 1.5 years or more before participating in the study. Also, the patients must have subsequently developed ipsilateral upper-limb lymphedema with a difference of $2 \mathrm{~cm}$ or more at any one measurement point or $200 \mathrm{~mL}$ or more compared with the contralateral upper limb. Patients were excluded if they had primary lymphedema, secondary lymphedema due to other system pathology, stage III lymphedema, bilateral disease, diagnosed cancer recurrence, and any contraindication to the affected upper-limb exercises (e.g., venous thrombosis). 


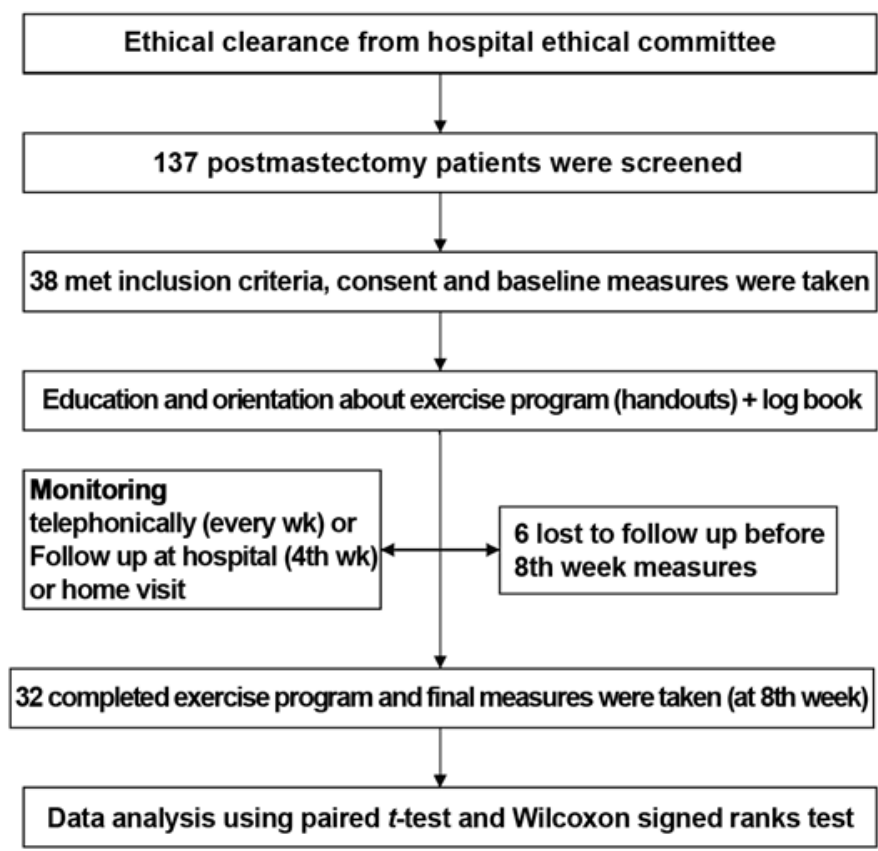

Figure.

Flow of participants through study.

\section{Measurements}

All the measurements were taken at baseline and at the completion of 8 weeks of the home-based exercise program.

\section{Lymphedema Measurement}

Lymphedema was measured two ways: using circumferential measurements and a volumetric method. Patients using compression sleeves were advised to remove them 3 to 4 hours before the following measurements were taken:

1. Upper-limb circumference was taken using cloth measuring tape on bilateral upper-limbs at four levels, i.e., at the metacarpophalangeal joints, wrist joint, $15 \mathrm{~cm}$ distal to the lateral epicondyle, and $10 \mathrm{~cm}$ proximal to the lateral epicondyle. Patients were positioned prone with their upper limbs at their sides and their elbows straight while the circumference measurements were taken [20-21]. Two measurements were taken and their mean was used. The calculated difference between each circumference (in centimeters) at all four levels between the affected and contralateral upper limbs was taken as outcome.

2. Volumetric measurements were taken by the water displacement method, which is based on Archimedes' Prin- ciple. Two readings were taken: (1) at the ulnar styloid process level and (2) $45 \mathrm{~cm}$ proximal to the ulnar styloid process level for each upper limb. During measurement, patients were advised to keep their upper limb straight and immerse it slowly by sliding their fingers straight down inside the wall of the volumeter, which was filled with water. Water displaced was collected from the point of immersion of upper limb until the marked level was reached and no further dripping of water was observed. The collected water was transferred into a graduated cylinder and the volumetric reading was taken to the nearest $5 \mathrm{~mL}$ level. This method of volumetric measurement has been used previously by McKenzie and Kalda [22]. The outcome measure was the calculated difference in volume (in milliliters) displaced between the affected and contralateral upper limbs.

\section{Quality of Life}

QOL was measured by using the 36-Item Short Form Health Survey (SF-36) QOL questionnaire. The SF-36 has been widely used as a reliable and valid tool to measure general QOL of patients with various medical conditions, including cancer. It is a 36-item scale with 8 major components that cover physical, social, and emotional functioning as well as vitality, bodily pain, mental health, and general health. Completely filled questionnaires were scored using the SF-36 Health Survey Manual and Interpretation Guide [37].

\section{Home-Based Exercise Program}

Education about postmastectomy lymphedema and the home-based exercise program (Table 1) was given before the initiation of the exercise program. A qualified physiotherapist gave the initial sessions of exercise prescription and training. Patients practiced the exercise sequence three to four times; once their performance was found satisfactory, the exercise program (handout) along with logbook were given to the patient. Patients were advised to increase the weight only when 2 sets of 15 repetitions became easy to perform. Patients were monitored telephonically every week and at a fourth-week follow up in the hospital or at home for those patients who were not able (30\%) to come in for follow up.

\section{Statistical Analysis}

Data were analyzed using SPSS version 16 (SPSS Inc; Chicago, Illinois) and Microsoft Excel 2007 (Microsoft Corp.; Redmond, Washington). 
Table 1.

Progressive resistance exercise program to enhance muscle strength and endurance of upper limb and scapular muscles (modified from Franklin et al. and Harris et al. [1-2]). Participants used household items (e.g., water bottle, salt packets).

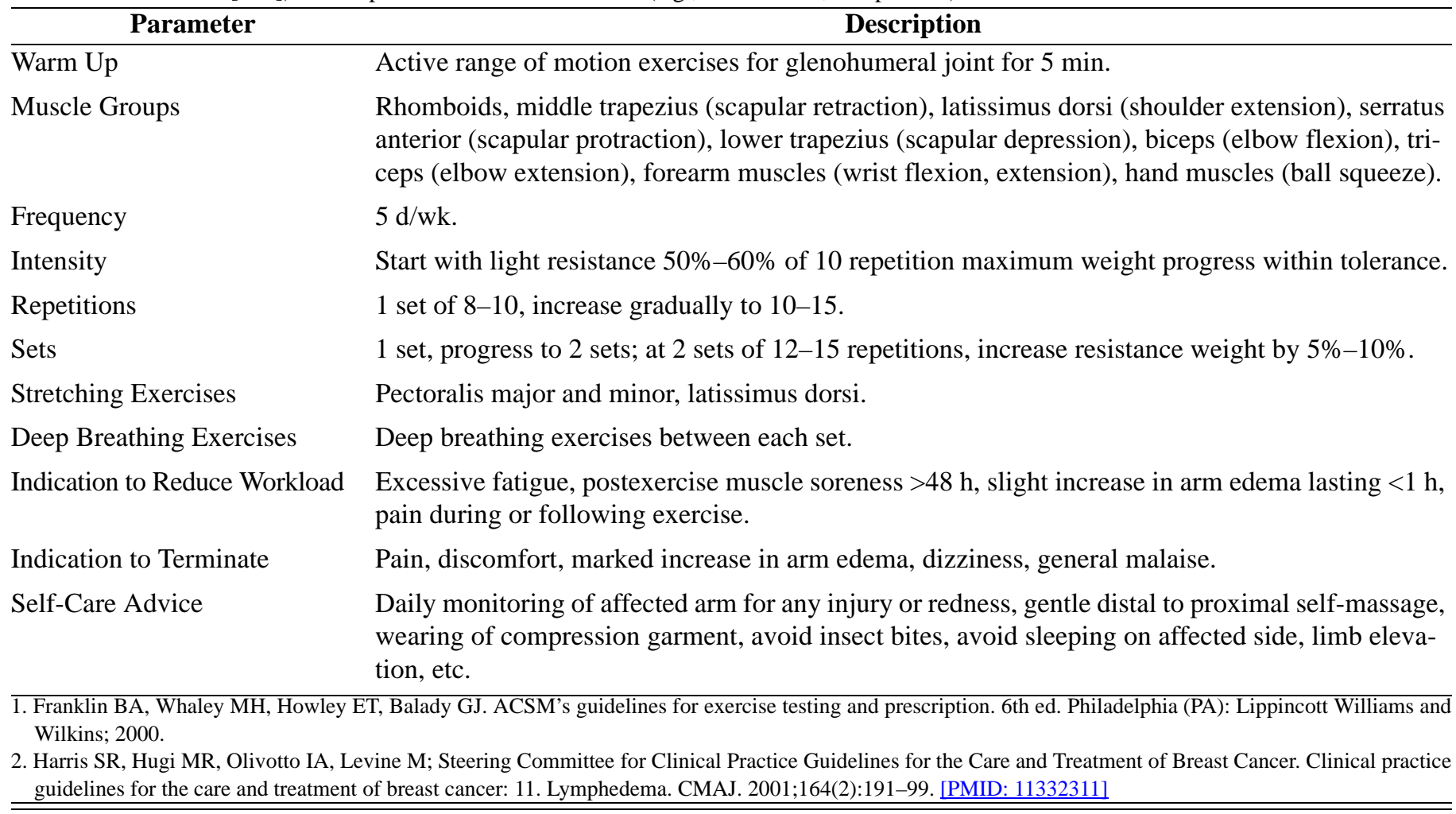

Descriptive analysis was done for patient age and time since mastectomy. Paired $t$-tests were used for comparison of mean values of the pre- and postexercise circumferential and volumetric measurements and the Wilcoxon signed ranks test was used for SF-36 QOL scores. The significance level was set at $p<0.01$ using Bonferroni correction $(\alpha / n=0.05 / 5=0.01)$.

\section{RESULTS}

The mean \pm standard deviation age of the postmastectomy lymphedema patients was $46.56 \pm 6.98$ years and time since mastectomy was $2.08 \pm 0.65$ years. A statistically significant reduction in affected upper-limb circumference was found at three levels of measurement $(p<0.001)$, except at the metacarpophalangeal joint level $(p=0.04)$ and in the affected upper-limb volume $(p<$ 0.001) (Table 2) following the 8-week home-based exercise program. Also, a statistically significant difference was found for QOL scores in all SF-36 domains postint- ervention (Table 3). Result analysis of the data is shown in Tables 2 and 3.

\section{DISCUSSION}

Lymphedema is a chronic, progressive, long-term adverse effect of breast cancer treatment resulting in affected upper-limb swelling, pain, heaviness, and discomfort. This not only affects the normal functional use of the affected upper limb but also causes psychological distress by altering the patient's body image because of visible swelling of the arm. Together, these symptoms greatly reduce QOL [14-15]. Several therapies have been used to treat lymphedema, but rehabilitative interventions remain the treatment mainstay and exercises play an important role in such rehabilitation.

Therefore, we carried out this study to evaluate the effect of an 8-week home-based exercise program of progressive resistance exercises, deep breathing, and self-care on the lymphedema and QOL of postmastectomy patients. The results of our study showed that the 
GAUTAM et al. Home-exercise program and postmastectomy lymphedema

Table 2.

Pre-post exercise program changes in affected upper-limb circumference and volume. Data presented as mean \pm standard deviation.

\begin{tabular}{lccc}
\hline Measurement & Preexercise & Postexercise & Pre-Post Change \\
\hline MCP Joints $(\mathrm{cm})$ & $19.17 \pm 1.46$ & $19.03 \pm 1.37$ & $0.14 \pm 0.9$ \\
Wrist Joint $(\mathrm{cm})$ & $16.45 \pm 2.09$ & $16.20 \pm 1.96$ & $0.25 \pm 0.13$ \\
$15 \mathrm{~cm}$ DLE $(\mathrm{cm})$ & $22.16 \pm 3.11$ & $21.47 \pm 2.83$ & $0.69 \pm 0.28$ \\
$10 \mathrm{~cm}$ PLE $(\mathrm{cm})$ & $31.02 \pm 4.38$ & $30.06 \pm 4.44$ & $0.96 \pm 0.06$ \\
Volume (mL) & $2306.32 \pm 627.82$ & $2183.49 \pm 597.45$ & $122.83 \pm 30.37$ \\
\hline DLE = distal to lateral epicondyle, MCP = metacarpophalangeal, PLE = proxi- \\
mal to lateral epicondyle.
\end{tabular}

home-based exercise program led to statistically significant reductions in the circumference and volume (Table 2) of the affected upper limb and improved QOL scores (Table 3) of breast cancer patients. Providing a logbook and continuous monitoring resulted in good adherence to the exercise program (89\% as per logbook records). Mean change in arm volume was $122 \mathrm{~mL}$. In fact, in our study, exercise acted as a therapeutic intervention instead of worsening the lymphedema symptoms.

Many justifications can be given regarding the use of gradual, progressive upper-limb exercise training along with deep breathing in the rehabilitation of lymphedema [19]. Gradually increasing the physiological stress to the affected upper limb through flexibility, resistance, and aerobic exercises will be better than inactivity in postmastectomy patients. Possible mechanisms by which affected upper-limb exercise improves or helps prevent lymphedema symptoms include that such exercise not only enhances lymphatic flow [38-41] but also improves protein resorption [42]. Lymphatic flow increases as a result of decreased intrathoracic pressure during inspiration phase [43]; this leads to speculation that increased pulmonary work during exercise may help in decreasing the lymphedema [44]. Also, affected upper-limb venous drainage has been found to be compromised most frequently in lymphedema patients [45]. Stretching exercises may help reduce the soft tissue contractures and, hence, decrease the blood and lymphatic obstruction [44].

Progressive resistance exercises may also cause selfcontraction of the lymphatic vessels by regulating sympathetic nerves innervating these vessels. Hence, the exercises enhance control over the internal contraction of these vessels by resetting their sympathetic drive, which in turn is important for the long-term management of lymphedema [38-39]. Because skeletal muscle contraction is a primary force in propelling lymph fluid throughout the lymphatic system, it can enhance lymphatic
Table 3.

Pre-post exercise program changes in 36-Item Short Form Health Survey quality of life scores.

\begin{tabular}{lccc}
\hline \multicolumn{1}{c}{ Parameter } & Preexercise & Postexercise & $\begin{array}{c}\text { Change in } \\
\text { Score }\end{array}$ \\
\hline Physical Function & 33.90 & 44.40 & 10.50 \\
Role Physical & 37.30 & 43.40 & 6.10 \\
Bodily Pain & 37.60 & 46.10 & 8.50 \\
General Health & 42.20 & 44.60 & 2.40 \\
Vitality & 45.80 & 52.10 & 6.30 \\
Social Function & 37.75 & 45.90 & 8.15 \\
Role Emotional & 32.60 & 44.20 & 11.60 \\
Mental Health & 37.30 & 44.40 & 7.10 \\
Physical Component Summary & 41.25 & 46.30 & 5.05 \\
Mental Component Summary & 38.55 & 48.30 & 9.75 \\
\hline \hline
\end{tabular}

clearance. Lane et al. injected an isotope into the hands of nondisabled women and determined that 5 minutes of exercises using an arm ergometer enhanced lymphatic clearance in the hand [30].

In addition, deep breathing while performing any exercise for lymphedema is doubly important. First, deep breathing is vital to ensure an adequate supply of oxygen to the tissues when the body is undergoing greater than usual exertion. Second, deep breathing creates pressure change in the abdomen, which acts like a vacuum in the thoracic cavity, helping to drain lymphatic vessels [44]. Moseley et al. reported that 38 women with secondary arm lymphedema who performed 10 minutes of gentle arm exercises combined with deep breathing everyday for 1 month achieved a statistically significant reduction in arm volume of $101 \mathrm{~mL}$ (9.0\%) [31]. In our study, we found a similar reduction in arm volume of $122 \mathrm{~mL}$, which might be due to longer duration of the exercise program compared with Moseley et al.'s study.

The contralateral upper limb was used as the control so that any physiological change in arm composition due to exercise would happen equally on both limbs. This method is similar to previous studies $[20,22]$. The outcome measures we used did not give accurate information regarding changes at the tissue level, but regular exercises cause hypertrophy of muscles and adipose tissue loss. Not much change was seen in arm circumference clinically, so any effect of exercise on lymphedema is unknown to us; other tissue changes may have occurred that masked any positive change regarding accumulation of lymphatic fluid.

The participants also reported improvement in their affected upper-limb health (i.e., decreased pain, heaviness, 
and discomfort along with softening of fibrotic areas during daily household work) due to the exercise program. Many participants continued doing the exercises even after completion of the study period. Results showed a trend toward improved QOL scores in all aspects, including physical, social, and emotional well-being as well as general and mental health and vitality scores after the completion of the prescribed home-based exercise program (Table 3). Increase in physical functioning scores proved the fact that affected upper-limb progressive resistance exercises had a beneficial effect on postmastectomy lymphedema. Participants reported more confidence in using the affected upper limb during regular household work and were even able to lift groceries with ease. Due to this, they were less often reminded of having lymphedema, which may have improved vitality and general health scores. These results are similar to the study by McKenzie and Kalda, which was also an 8-week exercise program [22]. Recent studies by Ahmed et al. and Schmitz et al. reported 80 and 88 percent adherence rates to twice a week supervised exercise programs for 6 months and 1 year, respectively [23,25]; in our study, adherence was found to be 89 percent. Reason for this may be that the selfdirected exercise program for a short period of 8 weeks included many features thought to comprise effective home training, including baseline evaluation, written guidelines for home exercise, education about the exercise monitoring and self-care, daily activities log, once weekly telephonic monitoring by the therapist, and interim evaluation (fourth week). It may also be the fact that self-directed exercises performed in the home and community facilities are more convenient, and therefore, participants adhered more to the prescribed exercise program. In our study, none of the participants reported increased lymphedema symptoms as a result of the exercise program.

The prescribed 8-week home-based exercise program improved the affected upper-limb symptoms and also led to improved QOL. Home-based exercise programs should be considered for improving the symptoms of lymphedema resulting from breast cancer treatments.

Lack of an appropriate control group and a small sample size were two important limitations of our study. Also, we did not follow the patients to determine the long-term effects of the exercise program. Long-term studies with larger sample sizes and appropriate control groups should be undertaken. Studies should also be done comparing effects of home-based versus institution-based exercise programs.

\section{CONCLUSIONS}

A home-based exercise program was found to effectively improve affected upper-limb symptoms and led to improved QOL of breast cancer patients. Hence, this homebased exercise program should be considered for improving the secondary lymphedema and associated symptoms resulting from breast cancer treatments.

\section{ACKNOWLEDGMENTS}

\section{Author Contributions:}

Study concept and design: A. P. Gautam, A. G. Maiya. Acquisition of data: A. P. Gautam.

Analysis and interpretation of data: A. P. Gautam.

Drafting of manuscript: A. P. Gautam.

Critical revision of manuscript for important intellectual content:

A. G. Maiya, M. S. Vidyasagar.

Statistical analysis: A. P. Gautam.

Administrative, technical, or material support: M. S. Vidyasagar.

Study supervision: A. G. Maiya, M. S. Vidyasagar.

Financial Disclosures: The authors have declared that no competing interests exist.

Funding/Support: This material was unfunded at the time of manuscript preparation.

Institutional Review: Ethical clearance for the study was approved by the hospital ethical committee. A written consent for willing participation in the home-based exercise program was taken from all the patients before the baseline measures.

Participant Follow-Up: The authors do not plan to inform participants of the publication of this study. However, participants for whom contact information is available have been encouraged to check the study Web site for updated publications.

\section{REFERENCES}

1. Sakorafas GH, Peros G, Cataliotti L, Vlastos G. Lymphedema following axillary lymph node dissection for breast cancer. Surg Oncol. 2006;15(3):153-65. [PMID: 17187979] http://dx.doi.org/10.1016/j.suronc.2006.11.003

2. Coen JJ, Taghian AG, Kachnic LA, Assaad SI, Powell SN. Risk of lymphedema after regional nodal irradiation with breast conservation therapy. Int J Radiat Oncol Biol Phys. 2003;55(5):1209-15. [PMID: 12654429]

http://dx.doi.org/10.1016/S0360-3016(02)04273-6

Erratum in: Int J Radiat Oncol Biol Phys. 2003;56(2):604.

3. Hinrichs CS, Watroba NL, Rezaishiraz H, Giese W, Hurd T, Fassl KA, Edge SB. Lymphedema secondary to postmastectomy radiation: Incidence and risk factors. Ann Surg Oncol. 2004;11(6):573-80. [PMID: 15172932]

http://dx.doi.org/10.1245/ASO.2004.04.017 
4. Erickson VS, Pearson ML, Ganz PA, Adams J, Kahn KL. Arm edema in breast cancer patients. J Natl Cancer Inst. 2001;93(2):96-111. [PMID: 11208879] http://dx.doi.org/10.1093/jnci/93.2.96

5. Petrek JA, Senie RT, Peters M, Rosen PP. Lymphedema in a cohort of breast carcinoma survivors 20 years after diagnosis. Cancer. 2001;92(6):1368-77. [PMID: 11745212] http://dx.doi.org/10.1002/10970142(20010915)92:6<1368::AID-CNCR1459>3.0.CO;2-9

6. Hayes S, Cornish B, Newman B. Comparison of methods to diagnose lymphedema among breast cancer survivors: 6month follow-up. Breast Cancer Res Treat. 2005;89(3): 221-26. [PMID: 15754119] http://dx.doi.org/10.1007/s10549-004-2045-x

7. Ozaslan C, Kuru B. Lymphedema after treatment of breast cancer. Am J Surg. 2004;187(1):69-72. [PMID: 14706589$]$ http://dx.doi.org/10.1016/j.amjsurg.2002.12.003

8. Tengrup I, Tennvall-Nittby L, Christiansson I, Laurin M. Arm morbidity after breast-conserving therapy for breast cancer. Acta Oncol. 2000;39(3):393-97. [PMID: 10987237] http://dx.doi.org/10.1080/028418600750013177

9. Shih YC, Xu Y, Cormier JN, Giordano S, Ridner SH, Buchholz TA, Perkins GH, Elting LS. Incidence, treatment costs, and complications of lymphedema after breast cancer among women of working age: A 2-year follow-up study. J Clin Oncol. 2009;27(12):2007-14. [PMID: 19289624] http://dx.doi.org/10.1200/JCO.2008.18.3517

10. Clark B, Sitzia J, Harlow W. Incidence and risk of arm oedema following treatment for breast cancer: A three-year follow-up study. QJM. 2005;98(5):343-48.

[PMID: 15820971]

http://dx.doi.org/10.1093/qjmed/hci053

11. Petrek JA, Heelan MC. Incidence of breast carcinomarelated lymphedema. Cancer. 1998;83(12 Suppl American): 2776-81. [PMID: 9874397]

12. Johansson K, Ohlsson K, Ingvar C, Albertsson M, Ekdahl C. Factors associated with the development of arm lymphedema following breast cancer treatment: A match pair case-control study. Lymphology 2002;35(2):59-71. [PMID: 12081053]

13. Armer JM, Stewart BR, Shook RP. 30-month post-breast cancer treatment lymphoedema. J Lymphoedema. 2009;4(1): 14-18. [PMID: 20182653]

14. Passik SD, McDonald MV. Psychosocial aspects of upper extremity lymphedema in women treated for breast carcinoma. Cancer. 1998;83(12 Suppl American):2817-20. [PMID: 9874404]

15. Pyszel A, Malyszczak K, Pyszel K, Andrzejak R, Szuba A. Disability, psychological distress and quality of life in breast cancer survivors with arm lymphedema. Lymphology. 2006; 39(4):185-92. [PMID: 17319631]
16. Harris SR, Campbell KL, McNeely ML. Upper extremity rehabilitation for women who have been treated for breast cancer. Physiother Can. 2004;56:202-14. http://dx.doi.org/10.2310/6640.2004.00022

17. Lymphedema: What every woman with breast cancer should know [Internet]. Atlanta (GA): American Cancer Society; 2009 (cited 2009 May 8). Available from: http:// www.cancer.org/Treatment/TreatmentsandSideEffects/ PhysicalSideEffects/Lymphedema/WhatEveryWomanwithBreastCancerShouldKnow/index.

18. Understanding breast cancer: After treatment: Life issues: Lymphedema [Internet]. Dallas (TX): Susan G. Komen for the Cure; 2009 (cited 2009 May 8). Available from: http://ww5.komen.org/BreastCancer/Lymphedema.html.

19. McKenzie DC. Abreast in a boat-A race against breast cancer. CMAJ. 1998;159(4):376-78. [PMID: 9732719]

20. Harris SR, Niesen-Vertommen S. Challenging the myth of exercise-induced lymphedema following breast cancer: A series of case reports. J Surg Oncol. 2000;74(2):95-99.

[PMID: 10914817]

http://dx.doi.org/10.1002/1096-

9098(200006)74:2<95::AID-JSO3>3.0.CO;2-Q

21. Harris SR, Hugi MR, Olivotto IA, Levine M; Steering Committee for Clinical Practice Guidelines for the Care and Treatment of Breast Cancer. Clinical practice guidelines for the care and treatment of breast cancer: 11. Lymphedema. CMAJ. 2001;164(2):191-99. [PMID: 11332311]

22. McKenzie DC, Kalda AL. Effect of upper extremity exercise on secondary lymphedema in breast cancer patients: A pilot study. J Clin Oncol. 2003;21(3):463-66. [PMID: 12560436] http://dx.doi.org/10.1200/JCO.2003.04.069

23. Ahmed RL, Thomas W, Yee D, Schmitz KH. Randomized controlled trial of weight training and lymphedema in breast cancer survivors. J Clin Oncol. 2006;24(18):2765-72.

[PMID: 16702582] http://dx.doi.org/10.1200/JCO.2005.03.6749

24. Kilbreath SL, Refshauge KM, Beith JM, Lee MJ. Resistance and stretching shoulder exercises early following surgery for breast cancer: A pilot study. Rehabil Oncol. 2006; 24(1):9-14.

25. Schmitz KH, Ahmed RL, Troxel A, Cheville A, Smith R, Lewis-Grant L, Bryan CJ, Williams-Smith CT, Greene QP. Weight lifting in women with breast cancer related lymphedema. N Engl J Med. 2009;361(7):664-73.

[PMID: 19675330]

http://dx.doi.org/10.1056/NEJMoa0810118

26. Schmitz KH, Troxel AB, Cheville A, Grant LL, Bryan CJ, Gross CR, Lytle LA, Ahmed RL. Physical activity and lymphedema (the PAL trial): Assessing the safety of progressive strength training in breast cancer survivors. Contemp Clin Trials. 2009;30(3):233-45. [PMID: 19171204] http://dx.doi.org/10.1016/j.cct.2009.01.001 
27. Box RC, Reul-Hirche H, Bullock-Saxton JE, Furnival CM. Physiotherapy after breast cancer surgery: Results of a randomised controlled study to minimise lymphedema. Breast Cancer Res Treat. 2002;75(1):51-64. [PMID: 12500934$]$ http://dx.doi.org/10.1023/A:1016591121762

28. Johansson K, Tibe K, Weibull A, Newton RC. Low intensity resistance exercise for breast cancer patients with arm lymphedema with or without compression sleeve. Lymphology. 2005;38(4):167-80. [PMID: 16515225]

29. Johansson K, Piller N. Weight-bearing exercise and its impact on arm lymphoedema. J Lymphoedema. 2007;2(1): $15-22$.

30. Lane KN, Dolan LB, Worsley D, McKenzie DC. Upper extremity lymphatic function at rest and during exercise in breast cancer survivors with and without lymphedema compared with healthy controls. J Appl Physiol. 2007;103(3): 917-25. [PMID: 17585046] http://dx.doi.org/10.1152/japplphysiol.00077.2007

31. Moseley AL, Piller NB, Carati CJ. The effect of gentle arm exercise and deep breathing on secondary arm lymphedema. Lymphology. 2005;38(3):136-45. [PMID: 16353491]

32. Trettin H. [Neurologic principles of edema in inactivity]. Z Lymphol. 1992;16(1):14-16. In German. [PMID: 1288027]

33. Thomas-Maclean RL, Hack T, Kwan W, Towers A, Miedema B, Tilley A. Arm morbidity and disability after breast cancer: New directions for care. Oncol Nurs Forum. 2008;35(1):65-71. [PMID: 18192154] http://dx.doi.org/10.1188/08.ONF.65-71

34. Turner J, Hayes S, Reul-Hirche H. Improving the physical status and quality of life of women treated for breast cancer: A pilot study of a structured exercise intervention. J Surg Oncol. 2004;86(3):141-46. [PMID: 15170652] http://dx.doi.org/10.1002/jso.20065

35. Cheema B, Gaul CA, Lane K, Fiatarone Singh MA. Progressive resistance training in breast cancer: A systematic review of clinical trials. Breast Cancer Res Treat. 2008; 109(1):9-26. [PMID: 17624588] http://dx.doi.org/10.1007/s10549-007-9638-0

36. Courneya KS, Segal RJ, Mackey JR, Gelmon K, Reid RD, Friedenreich CM, Ladha AB, Proulx C, Vallance JK, Lane K, Yasui Y, McKenzie DC. Effects of aerobic and resistance exercise in breast cancer patients receiving adjuvant chemotherapy: A multicenter randomized controlled trial. J Clin Oncol 2007;25(28):4396-4404. [PMID: 17785708] http://dx.doi.org/10.1200/JCO.2006.08.2024

37. Ware JE, Snow KK, Kosinski MK, Gandek B. SF-36 health survey manual and interpretation guide. Boston (MA): The Health Institute, New England Medical Center; 1993.
38. Witte CL, Witte MH. Contrasting patterns of lymphatic and blood circulatory disorders. Lymphology. 1987;20(4):171-78. [PMID: 3328023]

39. Witte MH, Witte CL. Lymphatics and blood vessels, lymphangiogenesis and hemangiogenesis: From cell biology to clinical medicine. Lymphology. 1987;20(4):257-66. [PMID: 2451095]

40. Mortimer PS. Investigation and management of lymphedema. Vasc Med Rev. 1990;1:1-20. http://dx.doi.org/10.1177/1358836X9000100102

41. Mortimer PS. Managing lymphoedema. Clin Exp Dermatol. 1995;20(2):98-106. [PMID: 8565266] http://dx.doi.org/10.1111/j.1365-2230.1995.tb02665.x

42. Leduc O, Bourgeois P, Leduc A. Manual of lymphatic drainage: Scintigraphic demonstration of its efficacy on colloidal protein resorption. In: Partsch $\mathrm{H}$, editor. Progress in lymphology IX. Amsterdam (the Netherlands): Elsevier; 1989. p. 421-23.

43. Wittlinger G, Wittlinger H, Harris RH. Textbook of Dr. Vodder's manual lymph drainage. New York (NY): Thieme; 2004.

44. Brennan MJ, Miller LT. Overview of treatment options and review of the current role and use of compression garments, intermittent pumps, and exercise in the management of lymphedema. Cancer. 1998;83(12 Suppl American):2821-27. [PMID: 9874405]

45. Svensson WE, Mortimer PS, Tohno E, Cosgrove DO. Colour Doppler demonstrates venous flow abnormalities in breast cancer patients with chronic arm swelling. Eur J Cancer. 1994;30A(5):657-60. [PMID: 8080682] http://dx.doi.org/10.1016/0959-8049(94)90539-8

Submitted for publication May 17, 2010. Accepted in revised form January 20, 2011.

This article and any supplementary material should be cited as follows:

Gautam AP, Maiya AG, Vidyasagar MS. Effect of homebased exercise program on lymphedema and quality of life in female postmastectomy patients: Pre-post intervention study. J Rehabil Res Dev. 2011;48(10):1261-68. DOI:10.1682/JRRD.2010.05.0089

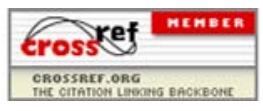

